\title{
Small Animal Imaging Resource Programs
}

National Cancer Institute

\section{Source}

National Cancer Institute. Small Animal Imaging Resource Programs. NCI Thesaurus. Code $C 15945$.

A program to improve access to researchers testing new approaches to diagnosis, treatment and prevention in animal models of cancer. Focus will be on functional, quantitative imaging. (Bypass Budget) 